\title{
Parent's knowledge about diagnosis and management of their children with congenital heart diseases in Khartoum, Sudan
}

\begin{abstract}
Background: Congenital heart defects (CHD) are the most common type of birth defects and remain the leading cause of death from congenital malformations.

Objectives: To assess the parent's knowledge regarding diagnosis and management of their children with CHD

Methods: This is a prospective questionnaire based study, conducted in Ahmed Gasim cardiac Centre, A tertiary care centre in Khartoum state, the study period was from $1 \mathrm{st}$ June to 31 st August of 2017.

Results: The total study population was 120 children with congenital heart disease and their parents. Of these children, males were $65(54.2 \%)$ and females were 55 $(45.8 \%)$. The children's age ranged from 2 months to $16 y e a r s$. The study showed that of these patients $76.7 \%$ had a cyanotic CHD with VSD being the commonest lesion found in $45 \%$ of them, while $23.3 \%$ of them had cyanotic CHD and TOF represented the most common lesion in $18.3 \%$ of them. For most of the parents the diagnosis of their children heart problem was explained to them, $78.3 \%$ of them knew correctly their children cardiac lesions, and $95.8 \%$ of them knew that it is congenital in origin, unfortunately $63.3 \%$ of them did not know the name of their children drugs and only $9.2 \%$ of them knew the side effects of their children's medications.

By using a knowledge score, 69 of these parents (57.5\%) displayed good knowledge Being an urban residents, younger in age and better educated all have a positive contribution to the amount of knowledge

Conclusion: As CHD, being one of the commonest congenital problems affecting children and their parents. The knowledge of the parents should be assessed and measures should be implemented to improve the knowledge of the parents, empowerment of the parents will improve the well being of children with CHD
\end{abstract}

Volume 8 Issue 6 - 2018

\section{Osama Hafiz Elshazali,' Hafiz Osama Hafiz El Shazali, ${ }^{2}$ Eiman Mohamed Ahmed Yousif, ${ }^{2}$ Hafiz El Shazali Osman'}

'Department of Paediatrics, University of Khartoum, Sudan ${ }^{2}$ Ahmed Gasim Children Hospital, Khartoum North, Sudan

\section{Correspondence: Osama Hafiz Elshazali,Associate Professor, Department of Paediatrics, University of Khartoum, Faculty of Medicine, University of Khartoum, PO Box 102, Khartoum, Sudan,Tel +2499|2325580,Email osamaelsazali@hotmail.com}

Received: April 16,2018 | Published: November 16, 2018

\section{Introduction}

Congenital heart disease (CHD) is the most common major congenital anomaly, representing a major global health problem. The incidence is $8-19$ per 1000 birth. $^{1}$ Congenital heart defects account for one third of babies with significant congenital anomalies diagnosed prenatally or in infancy. ${ }^{2}$ It has been shown that having an accurate understanding of any chronic condition contributes to improved satisfaction with medical care, less distress, less confusion, better compliance with treatment and an improved emotional state. Specifically for children with CHD, parents having a sound knowledge of their child's condition, treatment and prevention of complications has been shown to promote better health related behaviour in their child by bettering their understanding of the cardiac problem, improving compliance with treatment and avoiding risky behaviour. ${ }^{4}$ It is fundamental for patient engagement that they be health literate. This is more than just being able to read and understand health information it is about empowering them to exercise their autonomy. Patients with low health literacy have been shown to have poorer health status, are less likely to adhere to the treatment regimen and self-care plans, higher rates of hospital admission, experience more treatment and drug errors, and make less use of preventive services and measures. ${ }^{5}$ Recently there have been a massive improvement in therapy for congenital heart disease, both surgically and catheter based, despite this improvement several recent studies have shown that understanding of illness by children, adolescents, and adults with congenital heart disease remains far from ideal. ${ }^{4}$

\section{Methods}

This is cross-sectional questionnaire based survey parents who were accompanying their children to the outpatient clinic of Ahmed Gasim Cardiac Centre were recruited over a three month period. We excluded newly diagnosed children with congenital Heart Disease from the study. Ethical approval for the study was taken from the hospital ethical committee, Verbal and written consent were obtained from the parents after they had the study described to them. A pretested questionnaire including data of the patients such as age, gender, and residence, it also includes the demographic data of the parents including age, educational level, occupation, consanguinity, and socioeconomic status. A revised history, general and cardiovascular examination of the children was done to confirm the diagnosis and the information provided by the parents. From the medical records, some data was collected such as cardiac diagnosis, previous cardiac operations or cardiac catheterizations. 


\section{Statistical analysis}

Statistical Package for Social Sciences software, version 21.0 (IBM SPSSInc., Chicago, IL) was used for data analysis. Initially, all information gathered via questionnaire was coded into variables. Normality of data was tested using Kolmogorov-Smirnov test Both descriptive and inferential statistics involving binary logistic regression were used to present results. A $p$-value of less than 0.05 was considered statistically significant.

Score: Although the questionnaire used for assessing Knowledge, in order to have a better assessment of overall knowledge, each positive answer in the knowledge domain carried One mark while a negative answer carried Zero mark, this gave a total score range of $0-7$. The scores in knowledge domain was expressed as median (Not normally distributed). Knowledge was categorized as poor (score less than 5) and good (score of 5 and above).

\section{Results}

A total of 120 children with (CHD) were included in this study. Their parents were interviewed using the questionnaire to obtain the data. Of these patients $65(54.2 \%)$ were males and 55(45.8\%) were females. with male: female ratio of 1.2:1. Age distribution of the study group: 35 children (29.2\%) below one year of age, 51 children ( $42.5 \%)$ between one to five years of age, 20 children $(16.7 \%)$ between five to ten years of age and 14 children $(11.7 \%)$ were more than ten years of age (Figure 1). Most of the children in the study reside in urban areas $78(65 \%)$ in comparison to those in rural areas $42(35 \%)$. Maternal age distribution: $12(10 \%)$ mothers were less than 25years of age, 61 $(50.8 \%)$ were between 25-30years, $32(39.5 \%)$ between 31-35years, six $(5 \%)$ were between 36 -40years and two were more than 40years of age (Table 1). The majority of the mothers were housewives, $112(93.3 \%)$, only eight $(6.7 \%)$ were employed.

Mothers education: 40(33.3\%) mothers received primary education, $53(44.2 \%)$ mothers completed secondary school, and 13(10.8\%) mothers completed university (Figure 2). Six (5\%) mothers received no education, while eight $(6.7 \%)$ mothers received Al-khalwa education; Al-khalwa is a religious school that teaches fundamental religious and Arabic. ${ }^{6}$ Consanguinity between parents was found in $85(70.9 \%)$ of the Study group, first degree cousins constituted 59 (49.2\%) couples, 26 were second degree cousins (21.7\%). Family history of CHD was found in 15(12.2\%), while 105(87.5\%) had no family history of CHD. Regarding socio-economic status, $62(51.7 \%)$ of the parents were of moderate social class, while 58(48.3\%) of the parents were of low social class. The study showed that $92(76.7 \%)$ of the patients had a cyanotic CHD while $28(23.3 \%)$ of the patients had cyanotic CHD (Table 2). Most of the patients 96(80\%) were on medical treatment, and all were taking their medication regularly. $12(10 \%)$ of them had undergone catheterization, and $14(11.7 \%)$ of the patients had undergone surgery. In $117(97.5 \%)$ the diagnosis of their children heart problem was explained to them, 94(78.3\%) of them knew correctly their children cardiac lesions and 115(95.8\%) of them knew that it is congenital in origin. 76 out 96 who were on medical treatment $(79.2 \%)$ did not know the name of their children drugs and only eleven of them (11.5\%) knew the side effects of the medications. $84(87.5 \%)$ knew the correct dose of their children medications.

Most of them 73(60.8\%) knew that their children cardiac problems can be treated.

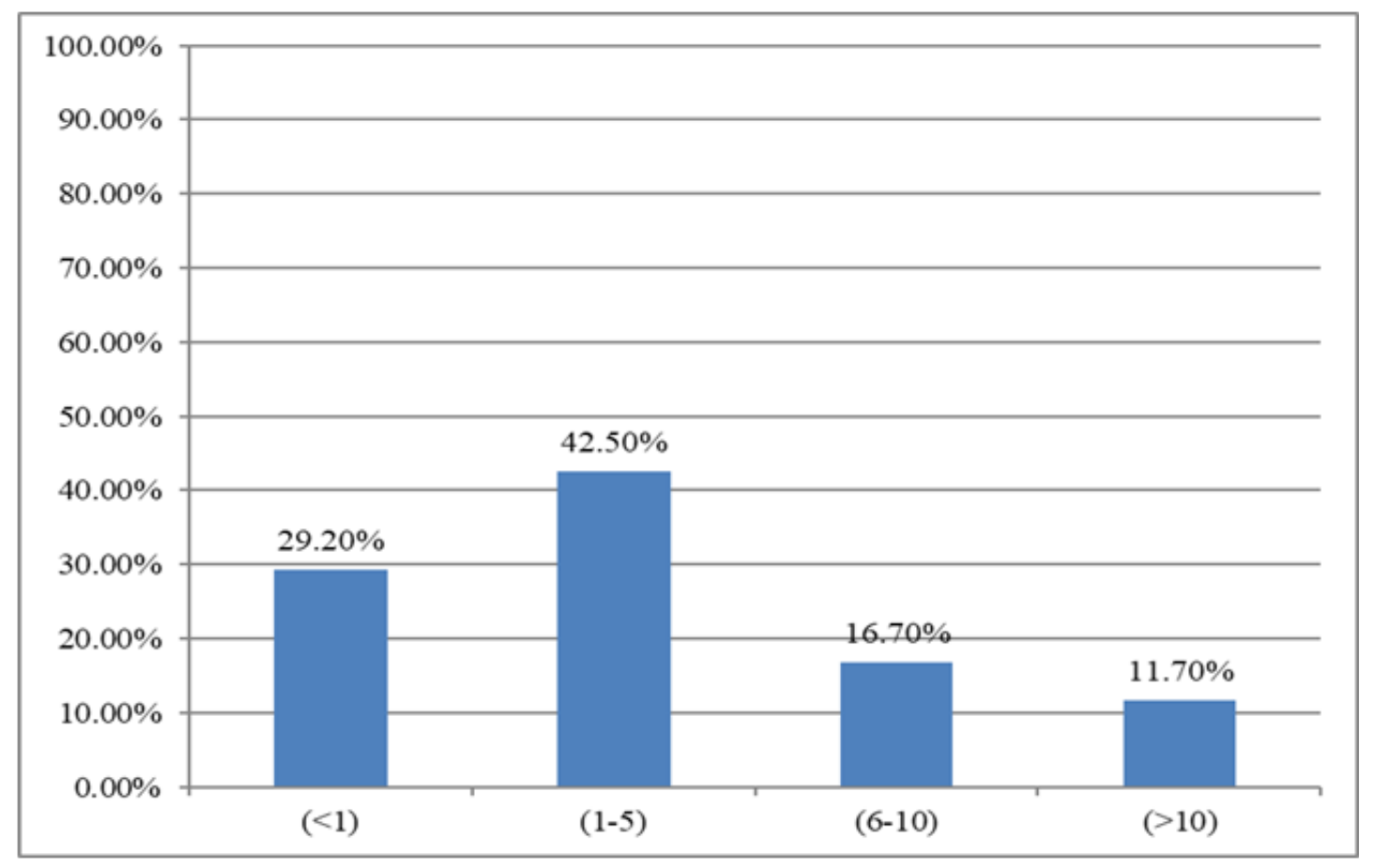

Figure I Children's age distribution. 


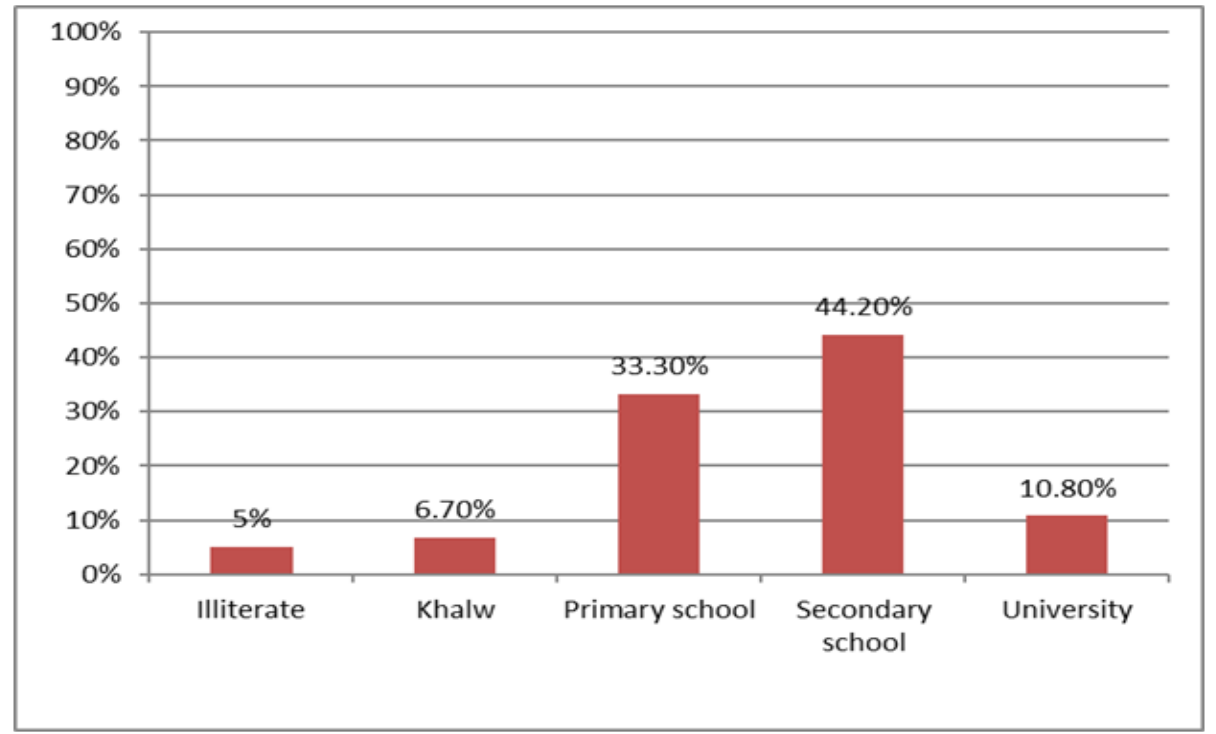

Figure 2 Mother's education.

Table I Maternal age of study group

\begin{tabular}{lll}
\hline Mother age(Years) & Frequency & Percent \\
\hline$(<25)$ & 12 & $10 \%$ \\
$(25-30)$ & 61 & $50.80 \%$ \\
$(31-35)$ & 39 & $32.50 \%$ \\
$(36-40)$ & 6 & $5 \%$ \\
$(>40)$ & 2 & $1.70 \%$ \\
Total & 120 & $100 \%$ \\
\hline
\end{tabular}

Table 2 Echocardiography findings

\begin{tabular}{lll}
\hline Echo findings & Frequency & Percent \\
\hline VSD & 54 & $45 \%$ \\
TOF & 22 & $18.30 \%$ \\
ASD & 17 & $14.10 \%$ \\
PDA & 11 & $9.30 \%$ \\
Others & 9 & $7.50 \%$ \\
PS & 3 & $2.50 \%$ \\
VSD and ASD & 2 & $1.70 \%$ \\
TGA & 1 & $1.60 \%$ \\
Total & 120 & $100 \%$ \\
\hline
\end{tabular}

\section{Discussion}

One hundred twenty patients were included in this study, in this study males predominated $(54.2 \%)$ over females $(45.8 \%)$, the ratio was 1.2:1 this consistent with Ibrahim, Abdelrahman \& Elshazali ${ }^{7}$ study ; which was done in the same centre where this study was conducted, and also consistent with El $\mathrm{Hag}^{8}$ study. Age of studied patients shows that the majority of patients $(71.7 \%)$ were less than 5 years old, ages ranging between 2 months and 16 years. The majority of the study population came from urban areas (65\%) although
$70 \%$ of Sudan population lives in rural areas, ${ }^{9}$ this was consistent with Mohammed ${ }^{10}$ study done in Sudan which indicated that urban population benefited more from health service compared to rural area. The majority of maternal ages were between 25 -35years (50.8\%), this reflects the pattern of maternal age in our community and this is in keeping with other studies from Sudan. ${ }^{11}$ Maternal education profile is similar to other studies done in Sudan. ${ }^{9}$ Most of the mothers in this study were housewives $(93.3 \%)$ this correlate with Mohammed $^{10}$ study, but this is different from World Bank ${ }^{12}$ data, which showed the Percentage of working woman in Sudan is $25.7 \%$, this could be explained that mothers with children with chronic illness e.g. CHD tend to stay at home to look after them.

Regarding knowledge about their child's CHD, 78.3\% of them mentioned their children heart problem correctly which was more than that reported in the study done by Cheuk et al., ${ }^{4}$ in Hong Kong which showed that only $59 \%$ could report their child problem , a study from Sudan by Mohammed ${ }^{10}$ reported that only $30 \%$ of parents mentioned the correct diagnosis. This may reflect the improvement in knowledge and may indicate that more time has been spent counseling the parents about the disease. $95.8 \%$ of the parents correctly mentioned that the heart defect was congenital, this percentage is good compared to other studies; in Cheuk et al., ${ }^{4}$ study, only half of the parents were aware of the possible etiology. This may indicate more knowledge among our study group. Of the 96 parents $(80 \%)$ whom their children were on regular medications $63.7 \%$ knew the name of the medications, this is comparable to Mohammed ${ }^{10}$ study. Of them $87.5 \%$ knew the dose and schedule of the medication, but only $(9.2 \%)$ of the parents in the study were aware of the side effects of these medications this is consistent with Mohammed ${ }^{10}$ study from Sudan and Cheuk et al., ${ }^{4}$ study from Hong Kong.

Parents knowledge in the area of side effects of medications seems to be poor in most of the studies, this area need to be addressed, in our situation parents collect their medication from different pharmacies, we have discussed this issue with our center pharmacist and since then we have started to give written information regarding the medication dosing and side effects in the clinic. Study from UK by Veldtman et al., ${ }^{3}$ done on patients with congenital heart disease, showed that Only 
$22 \%$ of the patients knew their diagnoses by name; $36 \%$ had a wrong or poor understanding of the nature of their cardiac abnormality, 33\% had a partial understanding, while only $30 \%$ had a good understanding of their illness. 29(37.2\%) parents who live in urban area, had good knowledge compared to $20 \%$ of those who live in rural areas, but this was statistically insignificant. There was no statistically significant difference in knowledge between younger and older parent, between educated and un uneducated parents or between low income and high income group (Table 3). Our study suggest that being young, well educated, living in urban area has a positive impact on knowledge

Table 3 Knoweldge score variables
, although there was no statistically significant difference, this is consistent with studies done by Mohammed ${ }^{10}$ and Cheuk et al., ${ }^{4}$ Although the results are good compared to other studies we feel that the knowledge of the parents could and should be improved. Evidence from the literature review suggests that well designed and written information, such as leaflets, can be useful learning aid when used in combined with professional consultation and advice .It improves health knowledge and later recall, it is most effective if the information is personalized. ${ }^{13,14}$

\begin{tabular}{|c|c|c|c|}
\hline \multirow{2}{*}{ Variables } & & \multicolumn{2}{|c|}{ Parents knowledge about children with congenital heart disease } \\
\hline & & Poor & Good \\
\hline \multirow{4}{*}{ Residence } & \multirow{2}{*}{ Urban } & 33 & 45 \\
\hline & & $27.50 \%$ & $37.50 \%$ \\
\hline & \multirow{2}{*}{ Rural } & 18 & 24 \\
\hline & & $15.00 \%$ & $20.00 \%$ \\
\hline \multirow{10}{*}{ Mother age(Years) } & \multirow{2}{*}{$(<25)$} & 6 & 6 \\
\hline & & $5.00 \%$ & $5.00 \%$ \\
\hline & \multirow{2}{*}{$(25-30)$} & 24 & 37 \\
\hline & & $20.00 \%$ & $30.80 \%$ \\
\hline & \multirow{2}{*}{$(31-35)$} & 16 & 23 \\
\hline & & $13.30 \%$ & $19.20 \%$ \\
\hline & \multirow{2}{*}{$(36-40)$} & 4 & 2 \\
\hline & & $3.30 \%$ & $1.70 \%$ \\
\hline & \multirow{2}{*}{$(>40)$} & 1 & 1 \\
\hline & & $0.80 \%$ & $0.80 \%$ \\
\hline \multirow{10}{*}{ Educational level } & \multirow{2}{*}{ Illiterate } & 3 & 3 \\
\hline & & $2.50 \%$ & $2.50 \%$ \\
\hline & \multirow{2}{*}{ Khalwa } & 4 & 4 \\
\hline & & $3.30 \%$ & $3.30 \%$ \\
\hline & \multirow{2}{*}{$\begin{array}{l}\text { Primary } \\
\text { school }\end{array}$} & 19 & 21 \\
\hline & & $15.80 \%$ & $17.50 \%$ \\
\hline & \multirow{2}{*}{$\begin{array}{l}\text { Secondary } \\
\text { school }\end{array}$} & 21 & 32 \\
\hline & & $17.50 \%$ & $26.70 \%$ \\
\hline & \multirow{2}{*}{ University } & 4 & 9 \\
\hline & & $3.30 \%$ & $7.50 \%$ \\
\hline \multirow{4}{*}{ Occupation } & \multirow{2}{*}{ Housewife } & 49 & 63 \\
\hline & & $40.80 \%$ & $52.50 \%$ \\
\hline & \multirow{2}{*}{ Employee } & 2 & 6 \\
\hline & & $1.70 \%$ & $5.00 \%$ \\
\hline \multirow{4}{*}{ Income } & \multirow{2}{*}{ Moderate } & 24 & 38 \\
\hline & & $20.00 \%$ & $31.70 \%$ \\
\hline & \multirow{2}{*}{ Low } & 27 & 31 \\
\hline & & $22.50 \%$ & $25.80 \%$ \\
\hline $\mathrm{N}=120$ & & & \\
\hline
\end{tabular}


On their own leaflets have minimal effect, however oral and written information used in conjunction can improve the patients experience and later may lead to reduced use of health service resources. Other tools, such as websites have been shown to have beneficial effects on health behaviour and self-efficacy; and higher user satisfaction. ${ }^{5}$ Various approaches to improving treatment adherence have been assessed. The most effective have been to simplifying the dosing program. The jury is still out on whether other interventions e.g. patient education, counselling and information can lead to improved adherence. ${ }^{15}$

\section{Conclusion}

The knowledge of the parents of children with congenital heart disease regarding their children disease was good, but there is a room for improvement. The area of treatment compliance and side effect of medication need to be addressed, simple measures like providing more information especially written information is beneficial.

\section{Acknowledgements}

None.

\section{Conflict of interest}

Author declares that there is no conflict of interest.

\section{References}

1. Hoffman JIE, Kaplan S. The incidence of congenital heart disease. J Am Coll Cardiol. 2002;39(12):1890-1900.

2. Dolk H, Loane M, Garne E. Congenital heart defects in Europe: Prevalence and perinatal mortality, 2000 to 2005. Circulation. 2011;123(8):841-849.

3. Veldtman GR, Matley SL, Kendall L, et al. Illness understanding in children and adolescents with heart disease. Heart (British Cardiac Society). 2000;84(4):395-397.
4. Cheuk DKL, Wong SMY, Choi YP, et al. Parents' understanding of their child's congenital heart disease. Heart. 2004;90(4):435-439.

5. Coulter A, Ellins J. Effectiveness of strategies for informing, educating, and involving patients. BMJ. 2007;335(7609):24-27.

6. Qarib Allah, AMAF. The philosophy and history of Al-Khalwa in the Sudan. ProQuest Dissertations and Theses. The Pennsylvania State University; 1988.

7. Ibrahim SA, Abdelrahman $\mathrm{MH}$, Elshazali OH. Pattern and Diagnosis of Congenital Heart Disease in Patients attending Ahmed Gasim Cardiac Centre. Sudan Journal of Medical Sciences. 2013;7:249-254.

8. El Hag A. Pattern of congenital heart disease in Sudanese children. East Afr Med J. 1994;71(9):580-586.

9. Ibnouf FO. The role of women in providing and improving household food security in Sudan: Implications for reducing hunger and malnutrition. Journal of International Women's Studies. 2009;10(4):144.

10. Mohammed L. Parental Knowledge, Attitudes and Practice towards Their Children' S Congenital Heart Disease and Its Impact on Their Growth in Sudan Heart Centre. University of Khartoum; 2015

11. Elshibly EM, Schmalisch G. The effect of maternal anthropometric characteristics and social factors on gestational age and birth weight in Sudanese newborn infants. BMC Public Health. 2008;8(1):244.

12. World Bank. Labour Force, female (\% of total labour force). World Bank Data. 2017.

13. McPherson CJ, Higginson IJ. Effective methods of giving information in cancer: a systematic literature review of randomized controlled trials. $J$ Public Health Med. 2001;23:227-234.

14. Johansson K, Nuutila L, Virtanen H, et al. Preoperative education for orthopaedic patients: systematic review. J Adv Nurs. 2005;50(2):212-223.

15. Haynes R, Yao X, Degani A, et al. Interventions to enhance medication adherence. Cochrane Database Syst Rev. 2005;4:CD000011. 